\title{
FAST DETERMINATION OF THE SULFUR SPECIES IN SOLID PHASE SYSTEMS BY A TPO-IR METHOD
}

\author{
Shiyun Tang ${ }^{\mathrm{a}, \mathrm{b}, *,(1)}$, Song Yang ${ }^{\mathrm{a}}$, Sheng Tan ${ }^{\mathrm{a}}$, Junjiang Guo and Anjiang Tang ${ }^{\mathrm{a}}$ \\ ${ }^{a}$ College of Chemical Engineering, Guizhou Institute of Technology, Guiyang, 550003, P. R. China \\ ${ }^{b}$ Guizhou Provincial Key Laboratory of Energy Chemistry, Guiyang 550003, P. R. China
}

Recebido em 26/06/2020; aceito em 21/09/2020; publicado na web em 28/10/2020

\begin{abstract}
Qualitative and quantitative assessment of total sulfur and sulfur species in solid phase is necessarily important for development of effective desulfurization methods, reduction of environmental pollution, and prevention of catalyst poisoned. In this work, TPO-IR (Temperature Programmed Oxidation- Infrared) method was used for rapid determination of sulfur species in solid minerals. The high purity of $\mathrm{Ag}_{2} \mathrm{~S}$ was used as the calibration materials at the fixed temperature of $1100{ }^{\circ} \mathrm{C}$, and the $\mathrm{TPO}$ experimental runs were performed on the solid minerals of phosphorite and coal. The results show that pyrite sulfur with $\mathrm{T}_{\max }$ of $426{ }^{\circ} \mathrm{C}$, and two thiophene sulfurs with $\mathrm{T}_{\max }$ of $450{ }^{\circ} \mathrm{C}$ and $481^{\circ} \mathrm{C}$ were found in Kaiyang phosphorite by fitting the TPO-IR curves; while pyrite sulfur with $\mathrm{T}_{\max }$ of $432{ }^{\circ} \mathrm{C}$, complex sulfide with $\mathrm{T}_{\text {max }}$ of $679{ }^{\circ} \mathrm{C}$ and sulfate sulfur with $\mathrm{T}_{\max }$ of $939{ }^{\circ} \mathrm{C}$ were found in Weng' an phosphorite. For Gas coal, the TPO-IR curves of sulfur release can be deconvoluted into seven individual curves, while that of Anthracite deconvoluted into four individual curves. In conclusion, the TPO-IR method has many advantages for determination of sulfur species in solid phase systems, such as less sample consumption, simple pretreatment, convenient operation and low cost, etc.
\end{abstract}

Keywords: sulfur species; solid minerals; TPO-IR method; rapid determination.

\section{INTRODUCTION}

It is generally known that sulfur is a harmful element in many fields. For example, in the environmental protection field, sulfur is easily oxidized to form $\mathrm{SO}_{2}$ at high temperature, which further reacts with $\mathrm{H}_{2} \mathrm{O}$ in the atmosphere to form acid rain; ${ }^{1}$ in the catalytic field, sulfur or sulfur species (eg. $\mathrm{H}_{2} \mathrm{~S}, \mathrm{SO}_{2}$ ) are prone to cause the catalyst poisoned $; 2$ in the coal chemical industry field, sulfur in coal gas will not only cause the catalyst poisoned, but also seriously corrode the equipment. ${ }^{3,4}$ Sulfur species and their content in the processing of solid minerals need to be considered in the process industry. Therefore, the rapid determination of sulfur species in solid minerals is of great significance for the development of effective desulfurization methods, reduction of environmental pollution caused by mineral processing, and prevention of catalyst poisoned.

In general, sulfur in solid minerals can be divided into inorganic and organic sulfur species. ${ }^{5}$ The inorganic sulfur species include disulphides and sulphates, which are embedded in the solid minerals. The organic sulfur species are chemically bonded to the organic matrix of the solid minerals. For coal, sulphate sulfur species occur in the form of calcium, iron and barium sulphates, but the amount is often negligible. Almost all of the inorganic sulfur species are present as the cubic pyrite or orthorhombic marcasite, while the organic sulfur species may occur in different forms of functional groups such as disulphides, aliphatic or aromatic thiols, aliphatic, aromatic or mixed sulphides and disulphides, heterocyclic compounds, thiophenes and condensed thiophenic structures. ${ }^{6}$ Three kinds of chemical methods, such as oxidation, pyrolysis and reduction, are used to identify sulfur species in solid minerals combined with some standard analytical methods. These analytical methodologies include classical chemical method (gravimetric method and titration method), ${ }^{7-9}$ oxidative microcoulometry, ${ }^{10,11}$ ultraviolet fluorescence, ${ }^{12,13}$ non-dispersive infrared (IR), ${ }^{14,15}$ X-ray fluorescence spectroscopy, ${ }^{16-18}$ rateometric colorimetry, ${ }^{19,20}$ potentiometric methods, ${ }^{21}$ gas chromatography, ${ }^{22,23} \mathrm{X}$-ray photoelectron spectroscopy (XPS) and X-ray absorption spectroscopy. ${ }^{6}$

*e-mail: 20150649@git.edu.cn
However, the pyrolysis and reduction technologies are mainly suitable for the determination of organic sulfur species, the traditional chemical method is tedious and time-consuming, while XPS and X-ray absorption spectroscopy methods need expensive instruments with high cost. Oxidation technology, especially temperature programmed oxidation (TPO) technology, is very suitable for qualitative and quantitative detection of all sulfur species in solid minerals. TPO has previously been used to study the structure of carbons such as nanotubes and nanofibres, ${ }^{24,25}$ anthracites, ${ }^{26,27}$ and other carbon materials. ${ }^{28,29}$ Similar to the TPO of carbons, the principle of TPO technology is based on the fact that the reaction between solid sulfur atoms and molecular oxygen often takes place at special active sites (such as structural defects, $\mathrm{S}$ atoms at the edge), thus relating the oxygen reactivity of solid sulfur atoms to their structure. In the TPO process, the more reactive sulfur is oxidized at lower temperature while the less reactive sulfur is oxidized at higher temperatures..$^{30,31}$

Until now, it is still very difficult to fully understand the variation of sulfur species and the determination of sulfur content in the processing of solid minerals. In this work, we will present a method for rapid determination of sulfur species in solid minerals by temperature programmed oxidation- infrared technology (TPO-IR). This work will be helpful to college students, researchers, analytical chemists and process engineers.

\section{EXPERIMENTAL}

\section{Experimental equipment}

Figure 1 shows a schematic diagram of the TPO-IR experimental apparatus. The device is mainly composed of four systems: gas supply system, high temperature oxidation system, infrared detection system, and data recording and control system. In the gas supply system, the moisture and particulates from the $\mathrm{O}_{2}$ (the purity is more than $99.5 \%$ ) are removed by a gas purifier filled with anhydrous magnesium perchlorate. The high temperature tubular furnace electrically heated, capable of heating 150 to $185 \mathrm{~mm}$ length of the hot zone area of the 


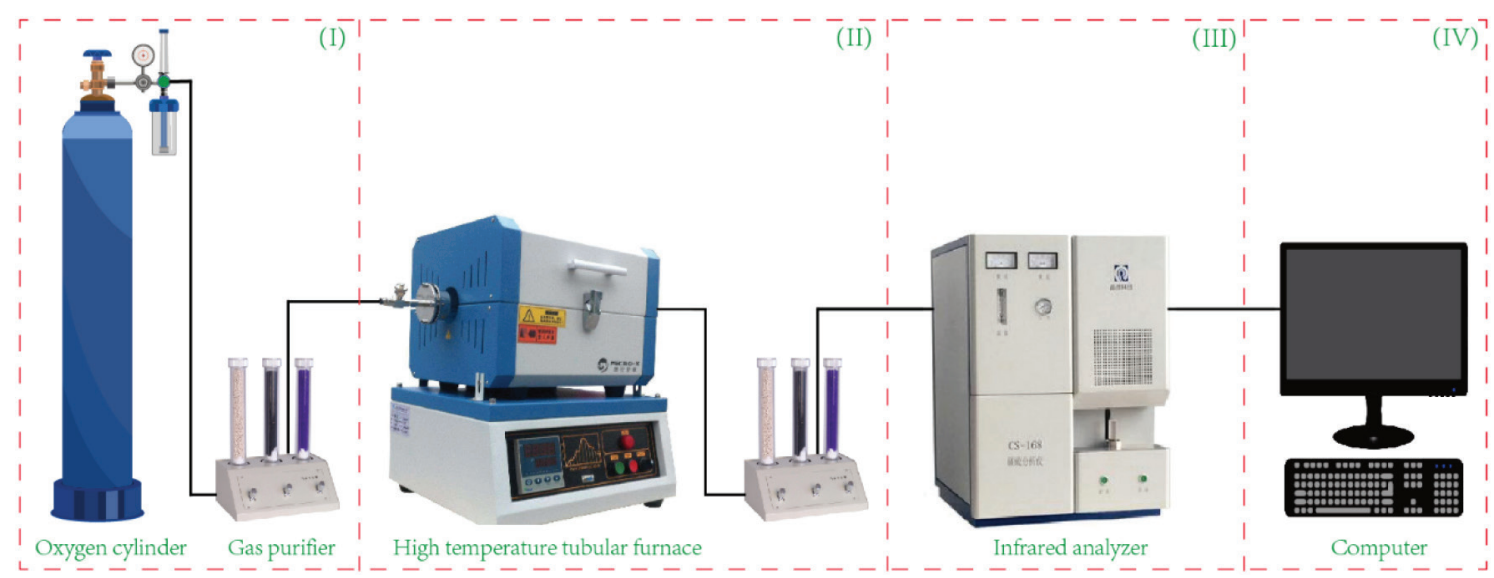

Figure 1. Schematic diagram of TPO-IR apparatus: I- gas supply system; II- high temperature oxidation system; III- infrared detection system; IV-data recording and control system

combustion tube to at least $1200{ }^{\circ} \mathrm{C}$. In the infrared analyzer, sulfur dioxide formed by high temperature oxidation or pyrolysis absorbs IR energy at a precise wavelength, and the concentration of sulfur dioxide is proportional to the change in energy at the detector. The data recording and control system is used to collect and analyze the detected signals, and control the whole process from lofting to giving the analysis results, so as to get the final analysis results.

\section{System calibration and operating conditions}

The qualitative and quantitative analysis of sulfur species is based on temperature programmed characteristic temperature method and constant temperature correction method, respectively. First of all, the calibration of quantitative analysis results is carried out at a fixed temperature of $1100{ }^{\circ} \mathrm{C}$. Silver sulfide $\left(\mathrm{Ag}_{2} \mathrm{~S}\right.$, purity $\left.\geq 99.995 \%\right)$ was used as the calibration materials in this work. The $\mathrm{Ag}_{2} \mathrm{~S}$ sample was ground $(<100 \mu \mathrm{m})$ to reduce the effect of mass transfer. The standard samples with different mass (range of $10 \mathrm{mg}-150 \mathrm{mg}$ ) were weighed accurately with a one hundred thousandth balance. Samples were stored in a ceramic boat which was calcined at $1300{ }^{\circ} \mathrm{C}$ for $8 \mathrm{~h}$. The tube furnace was heated at a predetermined rate (typically $5-15{ }^{\circ} \mathrm{C} \mathrm{min}^{-1}$ ) from room temperature to $1100{ }^{\circ} \mathrm{C}$ and finally fixed at $1100{ }^{\circ} \mathrm{C}$ for standard sample test. The standard samples were determined by constant temperature $\left(1100^{\circ} \mathrm{C}\right)$ with an oxygen flow of $1.80 \mathrm{~L} \mathrm{~min}^{-1}$. The operating conditions with the instrument parameters were listed in Table 1 . These parameters were selected according to the characteristics of $\mathrm{SO}_{2}$ emission from oxidation of the selected standard samples under high temperature. Before the test, the blank oxygen signal was collected as the baseline under the test conditions. When the baseline signal is stably collected, the sample was pushed into the high temperature zone of the tubular furnace immediately, and the push rod was pulled out quickly to avoid damaging by high temperature. As the sample completely releases the sulfur signal, the data collection can be stopped and the next round of sample testing can be carried out. To prevent the formation of $\mathrm{SO}_{2}$ pollution

Table 1. The operating conditions with the instrument parameters for system calibration

\begin{tabular}{ccc}
\hline Serial number & Project & Value \\
\hline 1 & Furnace temperature $\left({ }^{\circ} \mathrm{C}\right)$ & 1100 \\
2 & Flow of oxygen $(\mathrm{L} / \mathrm{min})$ & 1.80 \\
3 & Run time $(\mathrm{s})$ & 300 \\
4 & Blank acquisition time (s) & 60 \\
\hline
\end{tabular}

environment, the tail gas is absorbed by sodium hydroxide solution. After analysis, the instrument should indicate the total sulfur mass.

In addition, in order to assess the correctness of analyte addition to the matrix, recoveries of analyte spike were estimated by analyzing a set of $\mathrm{Ag}_{2} \mathrm{~S}$ standards with $\mathrm{SiO}_{2}$ addition at a fixed temperature of $1100{ }^{\circ} \mathrm{C}$. The value of the recovery of spike was calculated using the following equation: Recovery $=\left(\mathrm{M}_{\mathrm{S1}}-\mathrm{M}_{\mathrm{S} 2}\right) / \mathrm{M}_{\mathrm{S} 0}$, where $\mathrm{M}_{\mathrm{S} 1}$ - measured value of $\mathrm{S}$ in $\mathrm{Ag}_{2} \mathrm{~S}$ standards with $\mathrm{SiO}_{2}$ addition, $\mathrm{M}_{\mathrm{S} 2}$ - measured value of $\mathrm{S}$ in $\mathrm{SiO}_{2}, \mathrm{M}_{\mathrm{S} 0}$ - theoretical value of $\mathrm{S}$ in $\mathrm{Ag}_{2} \mathrm{~S}$ standards. The obtained values of recovery of analyte addition are summarized in Table 2.

Table 2. Recovery test results of standard addition

\begin{tabular}{lccccc}
\hline Parameter & First & Second & Third & Forth & Fifth \\
\hline $\mathrm{M}_{\mathrm{S} 2}(\mathrm{mg})$ & 0.0883 & 0.0834 & 0.0876 & 0.0859 & 0.0840 \\
$\mathrm{M}_{\mathrm{S} 1}(\mathrm{mg})$ & 1.8853 & 1.8078 & 2.2081 & 1.7691 & 2.1823 \\
$\mathrm{M}_{\mathrm{S} 0}(\mathrm{mg})$ & 1.9670 & 1.9549 & 2.3048 & 1.8149 & 2.2551 \\
Recovery (\%) & 99.65 & 103.52 & 100.41 & 97.74 & 99.48 \\
\hline
\end{tabular}

\section{Sulfur species in solid minerals by a TPO-IR method}

The temperature programmed experimental runs were performed on the different solid minerals samples, namely: $\mathrm{Ag}_{2} \mathrm{~S}$ (origin: Aladdin Technology Co., Ltd.), FeS (origin: Aladdin Technology Co., Ltd.), Kaiyang phosphorite (origin: Kaiyang, Guizhou), Weng'an phosphorite (origin: Weng'an, Guizhou), Gas coal (origin: Yongchuan, Chongqing) and Anthracite (origin: Fengchun, Chongqing). Among them, $\mathrm{Ag}_{2} \mathrm{~S}$ and $\mathrm{FeS}$ samples were used to carry out TPO test for qualitative analysis of sulfur species, which is the temperature programmed characteristic temperature method mentioned above. The main components in phosphorite are $\mathrm{Ca}_{5}\left(\mathrm{PO}_{4}\right)_{3} \mathrm{~F}, \mathrm{SiO}_{2}$ and $\mathrm{MgCa}\left(\mathrm{CO}_{3}\right)_{2}$ (dolomite), ${ }^{32}$ while the element analysis results of coal are shown in Table 3.

Table 3. The element analysis results of coal

\begin{tabular}{lccccc}
\hline Sample & $\mathrm{C}, \mathrm{ad}(\%)$ & $\mathrm{H}, \mathrm{ad}(\%)$ & $\mathrm{O}, \mathrm{ad}(\%)$ & $\mathrm{N}, \mathrm{ad}(\%)$ & $\mathrm{S}, \mathrm{ad}(\%)$ \\
\hline Gas coal & 74.14 & 6.1 & 5.95 & 1.28 & 0.72 \\
Anthracite & 75.63 & 3.25 & 0.98 & 1.12 & 2.18 \\
\hline
\end{tabular}

Similar to system calibration, the ground solid minerals samples $(<100 \mu \mathrm{m})$ were weighed accurately and stored in a ceramic boat. Differently, the sample was pushed into the constant temperature 
zone of the tubular furnace before heating, and then collected the blank oxygen signal. After that, the tube furnace was heated at a predetermined rate of $10{ }^{\circ} \mathrm{C} / \mathrm{min}$ from room temperature to $1050{ }^{\circ} \mathrm{C}$ with an oxygen flow of $1.80 \mathrm{~L} / \mathrm{min}$. When the infrared analyzer software automatically records the release curve of $\mathrm{SO}_{2}$, the mass of sulfur curve is derived. The Origin software was used to deduct baseline peak fitting and output fitting peak information. Finally, the peak temperature $\left(\mathrm{T}_{\max }\right)$ was used as the qualitative characteristic temperature of sulfur species in solid minerals, and the content of sulfur species was quantified by fitting curve information. The calculation formula of sulfur species content is as follows:

$$
W_{i} \%=A_{i} /\left(A_{1}+A_{2}+\ldots+A_{n}\right) * 100 \%
$$

where the $W_{i}$ is the mass fraction of one sulfur species in the total sulfur species; $A_{i}$ is the peak area of a sulfur species obtained by peak splitting fitting; $n$ is the number of peaks.

\section{RESULTS AND DISCUSSION}

\section{Calibration curve and TPO-IR analysis of $\mathrm{Ag}_{2} \mathrm{~S}$ and $\mathrm{FeS}$}

The standard curve was measured with $\mathrm{Ag}_{2} \mathrm{~S}$ at a constant temperature of $1100{ }^{\circ} \mathrm{C}$, as shown in Figure 2(a). It can be seen that the fitted calibration curve presents a straight line with the $\mathrm{R}^{2}$ of 0.99932 , which suggests that the calibration of the instrument by $\mathrm{Ag}_{2} \mathrm{~S}$ is reliable. Figure 2(b) is the TPO-IR curve of $\mathrm{Ag}_{2} \mathrm{~S}$. It can be observed that $\mathrm{Ag}_{2} \mathrm{~S}$ has a strong $\mathrm{SO}_{2}$ emission peak at $487{ }^{\circ} \mathrm{C}$, and a weaker peak of $\mathrm{SO}_{2}$ release at $855^{\circ} \mathrm{C}$ and $991{ }^{\circ} \mathrm{C}$. The sharp peak at $487{ }^{\circ} \mathrm{C}$ was assigned to sever oxidation of the $\mathrm{Ag}_{2} \mathrm{~S}$, thus the
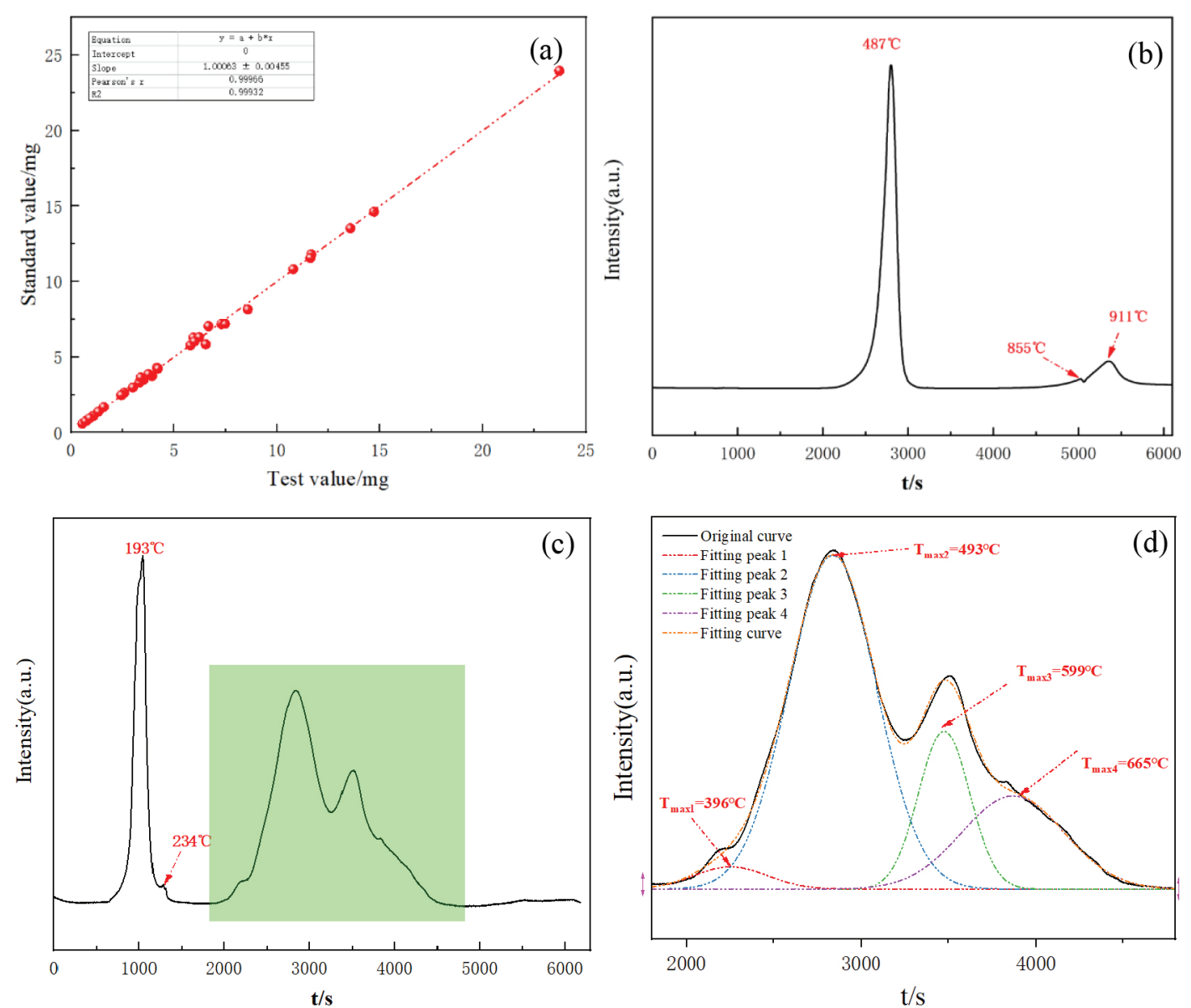

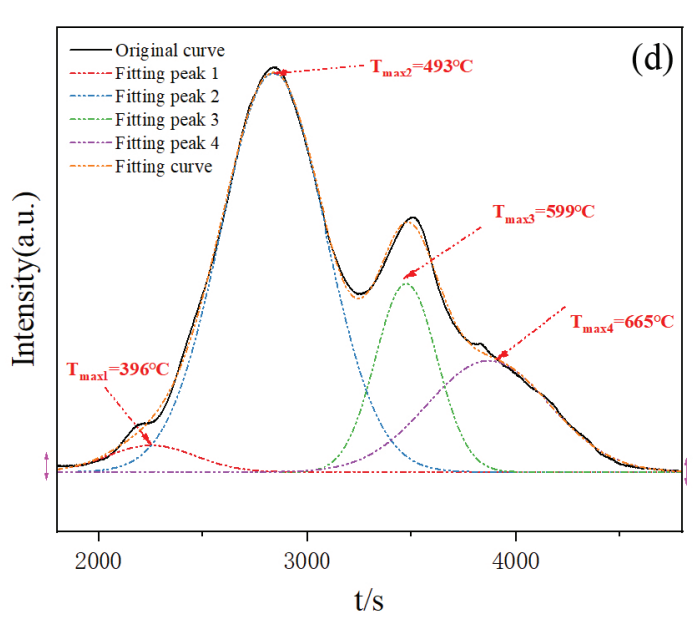

corresponding maximum peak temperature $\left(\mathrm{T}_{\max }\right)$ of $487{ }^{\circ} \mathrm{C}$ is the characteristic temperature of sulfur species in $\mathrm{Ag}_{2} \mathrm{~S}$. The peaks with the $\mathrm{T}_{\max }$ of $855{ }^{\circ} \mathrm{C}$ and $991{ }^{\circ} \mathrm{C}$ may be attributed to the release of $\mathrm{SO}_{2}$ from a small amount of silver sulfite and silver sulfate formed during the oxidation of $\mathrm{Ag}_{2} \mathrm{~S}$.

Figure 2(c) and 2(d) give the original and locally magnified TPOIR curves of FeS, respectively. Due to the unstable structure of FeS, the oxidation and release of $\mathrm{SO}_{2}$ are more complex. In the presence of trace moisture in the air, FeS is gradually oxidized to ferric oxide and sulfur. The chemical equation is as follows:

$$
3 \mathrm{FeS}(\mathrm{s})+2 \mathrm{O}_{2}(\mathrm{~g}) \rightarrow 3 \mathrm{~S}(\mathrm{~s})+\mathrm{Fe}_{3} \mathrm{O}_{4}(\mathrm{~s})
$$

Therefore, the $\mathrm{T}_{\max }$ of $198^{\circ} \mathrm{C}$ and $234^{\circ} \mathrm{C}$ belong to the oxidation peak of elemental sulfur which is formed by oxidation of FeS in air. At higher temperatures, the TPO-IR curves of FeS can be deconvoluted into four individual curves, corresponding to the $\mathrm{T}_{\max }$ of $396^{\circ} \mathrm{C}, 493{ }^{\circ} \mathrm{C}, 599^{\circ} \mathrm{C}$, and $665^{\circ} \mathrm{C}$, respectively. Therein the $\mathrm{T}_{\max }$ of $493{ }^{\circ} \mathrm{C}$ should be the characteristic temperature of sulfur specie in $\mathrm{FeS}$ and the remaining $\mathrm{T}_{\max }$ may be intermediate sulfides formed by oxidation of $\mathrm{FeS}$.

\section{TPO-IR analysis of phosphorite}

The composition of phosphorite is complex, and the composition of each producing area is also different. In addition to the main components of $\mathrm{Ca}_{5}\left(\mathrm{PO}_{4}\right)_{3} \mathrm{~F}, \mathrm{SiO}_{2}$ and dolomite, the phosphorite also contains a small amount of carbon and sulfur species. Figure 3(a) and (b) present the TPO-IR curves of phosphorite from Kaiyang and Weng'an. Three sulfur species were found in Kaiyang phosphorite by

Figure 2. Calibration curve (a), TPO-IR curves of $\mathrm{Ag}_{2} \mathrm{~S}(\mathrm{~b})$, and original (c) and locally magnified (d) TPO-IR curves of FeS 

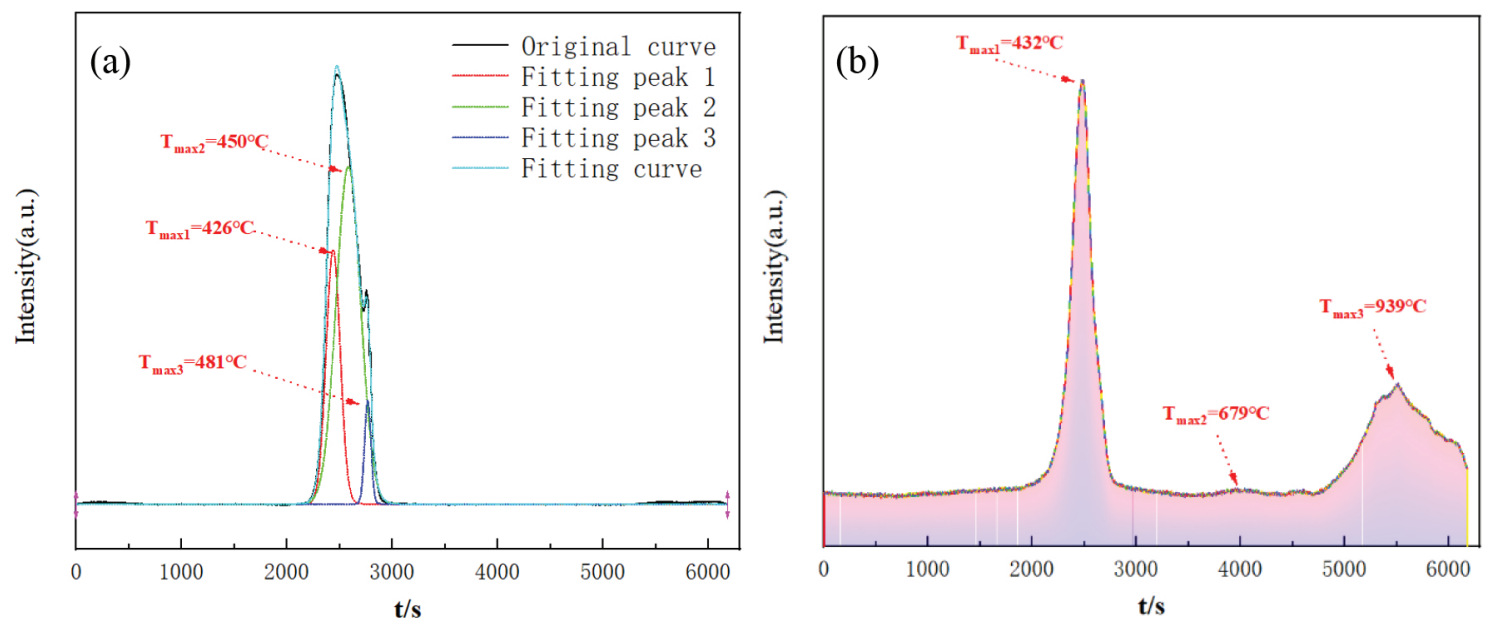

Figure 3. TPO-IR curves of phosphorite: (a) phosphorite from Kaiyang; (b) phosphorite from Weng'an

fitting the TPO-IR curves, corresponding $\mathrm{T}_{\max }$ of $426^{\circ} \mathrm{C}, 450^{\circ} \mathrm{C}$, and $481{ }^{\circ} \mathrm{C}$. According to the literature reports, the sulfur species with the $\mathrm{T}_{\max }$ of $426{ }^{\circ} \mathrm{C}$ may be pyrite sulfur, while the other two sulfur species with $\mathrm{T}_{\max }$ above $450{ }^{\circ} \mathrm{C}$ may be thiophene sulfur. ${ }^{33,34}$ For Weng' an phosphorite, there are at least three sulfur species, namely pyrite sulfur with $\mathrm{T}_{\text {max }}$ of $432{ }^{\circ} \mathrm{C}$, complex sulfide with $\mathrm{T}_{\max }$ of $679^{\circ} \mathrm{C}$ and sulfate sulfur with $\mathrm{T}_{\max }$ of $939^{\circ} \mathrm{C}$.

The content of sulfur species of phosphorite was calculated by fitting curves information and the results are summarized in Table 4. The total sulfur content of the two kinds of phosphorite is lower than $0.200 \%$, of which Kaiyang phosphorite is $0.194 \%$ which is far higher than $0.011 \%$ of Weng' an phosphorite. From the point of view of sulfur species, the two kinds of phosphorite have pyrite sulfur, but the content of pyrite sulfur in Kaiyang phosphorite $(0.058 \%)$ is much higher than that in Weng'an phosphorite $(0.006 \%)$. The content of thiophene sulfur in Kaiyang phosphorite is up to $0.136 \%$, while Weng'an phosphorite contains $0.005 \%$ of sulfate sulfur and no thiophene sulfur.

\section{TPO-IR analysis of coal}

Figure 4(a) and (b) present the TPO-IR curves of Gas coal and Anthracite, respectively. It can be seen that the sulfur in the coal is gradually released during the temperature programmed process, and the release temperature range is about $250-500{ }^{\circ} \mathrm{C}$. For Gas coal, the TPO-IR curves of sulfur release can be deconvoluted into seven individual curves, corresponding to the $\mathrm{T}_{\max }$ of $343{ }^{\circ} \mathrm{C}$, $347{ }^{\circ} \mathrm{C}, 354^{\circ} \mathrm{C}, 359{ }^{\circ} \mathrm{C}, 360{ }^{\circ} \mathrm{C}, 361^{\circ} \mathrm{C}$ and $390^{\circ} \mathrm{C}$, respectively. By contrast, the TPO-IR curves of Anthracite can be deconvoluted into four individual curves, corresponding to the $\mathrm{T}_{\max }$ of $360{ }^{\circ} \mathrm{C}, 371^{\circ} \mathrm{C}$, $372{ }^{\circ} \mathrm{C}$ and $385^{\circ} \mathrm{C}$, respectively. Theoretically, each $\mathrm{T}_{\max }$ corresponds to a sulfur species with a certain structure. At present, it is difficult to assign all these peaks in detail. This is because the sulfur species in coal are complex. Generally, the sulfur species of coal mainly include inorganic and organic sulfur species. ${ }^{35,36}$ Wherein, the inorganic sulfur species are present as the cubic pyrite or orthorhombic marcasite, while the organic sulfur species may occur in different forms of

Table 4. Comparison of sulfur analysis results between Kaiyang and Weng' an phosphorite

\begin{tabular}{ccccc}
\hline & & & \multicolumn{2}{c}{ Content of each sulfur species /\% } \\
\cline { 3 - 5 } Sample & $\begin{array}{c}\text { Content of total } \\
\text { sulfur / } \%\end{array}$ & $\begin{array}{c}\text { Pyrite sulfur } \\
\left(T_{\max } \text { of } 426{ }^{\circ} \mathrm{C}\right)\end{array}$ & $\begin{array}{c}\text { Thiophene sulfur } \\
\left(T_{\max } \text { of } 450^{\circ} \mathrm{C}\right)\end{array}$ & $\begin{array}{c}\text { Thiophene sulfur } \\
\left(T_{\max } \text { of } 481{ }^{\circ} \mathrm{C}\right)\end{array}$ \\
\hline Kaiyang & 0.194 & 0.058 & 0.126 & 0.010 \\
Weng'an & 0.011 & 0.006 & none & none \\
\hline
\end{tabular}
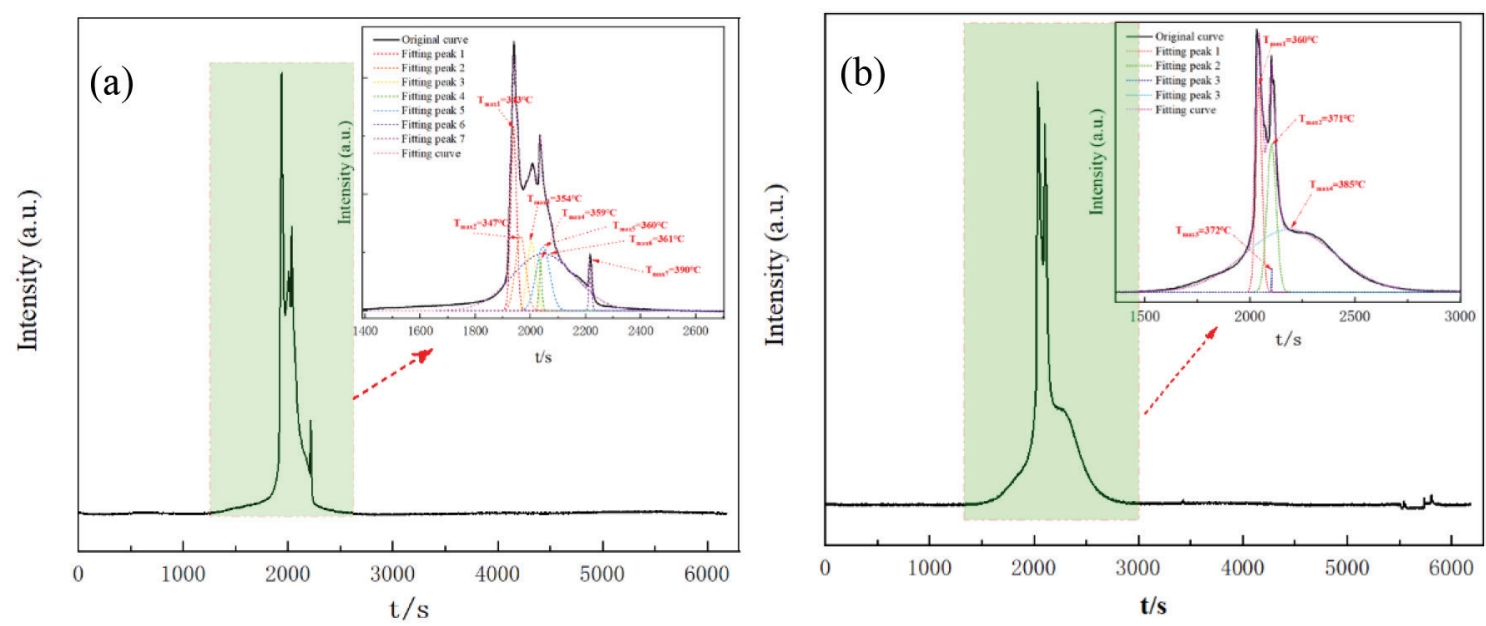

Figure 4. TPO-IR analysis of coal: (a) Gas coal; (b) Anthracite 
functional groups like disulphides, aliphatic or aromatic thiols, aliphatic, aromatic or mixed sulphides and disulphides, heterocyclic compounds, thiophenes or condensed thiophenic structures. ${ }^{6,36} \mathrm{Next}$ work, the standard samples of known sulfur species with different structures will be determined to assign complex sulfur species peaks. Only the total sulfur content of two coals is given here: $0.83 \%$ of Gas coal and $1.47 \%$ of Anthracite. It can be seen that the sulfur content in Anthracite is higher than that in Gas coal. Moreover, it is noteworthy that the sulfur content measured by TPO-IR method is not consistent with the results of elemental analysis of coal (see Table 2) due to the very uneven distribution of sulfur in coal. Compared with the data in Table 2, the sulfur content of Gas coal and Anthracite measured by TPO-IR method is $0.11 \%$ higher and $0.71 \%$ lower than the corresponding element analysis results.

To summarize, the advantage of TPO-IR method for determination of the sulfur species in solid phase systems is as follows:

(1) The amount of sample needed by TPO-IR method can be more or less, usually only a few tens of $\mathrm{mg}$, thus it conducive to the oxidation of sulfur species into sulfur dioxide release.

(2) TPO-IR method does not need to add any flux agent, which is beneficial to obtain the real intrinsic sulfur species and reduce the cost.

(3) The TPO-IR method is easy to operate, and the sample only needs simple crushing treatment, which is convenient and fast.

(4) In this work, sulfur species in solid minerals were oxidized or pyrolyzed by $\mathrm{O}_{2}$, and $\mathrm{SO}_{2}$ formed by oxidation or pyrolysis was monitored online by infrared analyzer. On the one hand, infrared analyzer has been widely used in total sulfur testing; on the other hand, the qualitative and quantitative detection of total sulfur and sulfur species can be realized by adjusting the temperature programmed rate once.

However, the disadvantage of current TPO-IR technology is that not all $\mathrm{T}_{\max }$ of peaks can be assigned. The key to solve this problem is to find the appropriate standard samples of known sulfur specialties with different structures for TPO-IR test.

\section{CONCLUSIONS}

Sulfur is a harmful element in many fields. The qualitative and quantitative assessment of total sulfur and sulfur species in solid phase systems is necessarily important for the development of effective desulfurization methods, reduction of environmental pollution caused by mineral processing, and prevention of catalyst poisoned. In this work, we present a TPO-IR method for rapid determination of sulfur species in solid minerals. The high purity of $\mathrm{Ag}_{2} \mathrm{~S}$ was used as the calibration materials at the fixed temperature of $1100{ }^{\circ} \mathrm{C}$, and the temperature programmed experimental runs were performed on the solid minerals of phosphorite and coal.

The fitted calibration curve presents a straight line with the $\mathrm{R}^{2}$ of 0.99932, which indicates that the calibration of the instrument by $\mathrm{Ag}_{2} \mathrm{~S}$ is reliable. Pyrite sulfur with $\mathrm{T}_{\max }$ of $426^{\circ} \mathrm{C}$, and two thiophene sulfurs with $\mathrm{T}_{\max }$ of $450{ }^{\circ} \mathrm{C}$ and $481{ }^{\circ} \mathrm{C}$ were found in Kaiyang phosphorite by fitting the TPO-IR curves; while pyrite sulfur with $\mathrm{T}_{\text {max }}$ of $432{ }^{\circ} \mathrm{C}$, complex sulfide with $\mathrm{T}_{\max }$ of $679{ }^{\circ} \mathrm{C}$ and sulfate sulfur with $\mathrm{T}_{\max }$ of $939^{\circ} \mathrm{C}$ were found in Weng' an phosphorite. For Gas coal, the TPO-IR curves of sulfur release can be deconvoluted into seven individual curves, corresponding to the $\mathrm{T}_{\text {max }}$ of $343{ }^{\circ} \mathrm{C}, 347^{\circ} \mathrm{C}, 354{ }^{\circ} \mathrm{C}, 359^{\circ} \mathrm{C}$, $360{ }^{\circ} \mathrm{C}, 361{ }^{\circ} \mathrm{C}$ and $390{ }^{\circ} \mathrm{C}$, respectively. By contrast, the TPO-IR curves of Anthracite can be deconvoluted into four individual curves, corresponding to the $\mathrm{T}_{\max }$ of $360{ }^{\circ} \mathrm{C}, 371{ }^{\circ} \mathrm{C}, 372{ }^{\circ} \mathrm{C}$ and $385{ }^{\circ} \mathrm{C}$, respectively. Theoretically, each $\mathrm{T}_{\text {max }}$ corresponds to a sulfur species with a certain structure. At present, it is difficult to assign all these peaks in detail due to the very complex sulfur species in coal.
In conclusion, the TPO-IR method has many advantages for determination of the sulfur species in solid phase systems, such as less sample consumption, simple pretreatment, convenient operation and low cost, etc.

\section{ACKNOWLEDGMENTS}

The research was supported by National Natural Science Foundation of China (No. 2176605), natural science foundation of Guizhou provincial department of education (Qianjiaohe KY Zi[2017] 009), High level talents research project of GIT and Undergraduate Training Programs for Innovation and Entrepreneurship.

\section{REFERENCES}

1. Vahedpour, M.; Zolfaghari, F.; Struct. Chem. 2011, 22, 1331.

2. Hiyoshi, N.; Sato, O.; Arai, K.; Shirai, M.; Energy Fuels 2008, 22, 845.

3. Zhang, L. J.; Li, Z. H.; He, W. J.; Li, J. H.; Qi, X. Y.; Zhu, J.; Zhao, L. M.; Zhang, X.; Fuel 2018, 222, 350.

4. Wang, C.; Luo, M.; Zhou, L. Z.; Zhang, H. Y.; Energy Fuels 2020, 34, 3969.

5. Qin, Z. H.; Zhang, H. F.; Dai, D. J.; Zhao, C. C.; Zhang, L. F.; J. Fuel Chem. Technol. 2014, 42, 1286.

6. Cloutis, E. A.; Fuel 2003, 82, 2239.

7. Standard test method for total sulfur in fuel gases by combustion and barium chloride titration. American Society for Testing and Material. D 1072. 2012.

8. Standard test method for sulfur in liquefed petroleum gases (oxyhydrogen burner or lamp). American Society for Testing and Material. D 2784. 2011.

9. Standard test method for sulfur in petroleum products (general highpressure decomposition device method). American Society for Testing and Material. D 129. 2013.

10. Standard test method for trace quantities of sulfur in light liquid petroleum hydrocarbons by oxidative microcoulometry. American Society for Testing and Material. D 3120. 2014.

11. Standard test method for sulfur in petroleum gas by oxidative microcoulometry. American Society for Testing and Material. D 3246. 2015 .

12. Standard test method for determination of total sulfur in light hydrocarbons, spark ignition engine fuel, diesel engine fuel, and engine oil by ultraviolet fluorescence. American Society for Testing and Material. D 5453. 2012.

13. Standard test method for determination of total volatile sulfur in gaseous hydrocarbons and liquefed petroleum gases and natural gas by ultraviolet fluorescence. American Society for Testing and Material. D 7551. 2015.

14. Standard test method for sulfur in petroleum products by high temperature combustion and IR detection. American Society for Testing and Material. D 1552. 2015.

15. Standard test method for total sulfur in coal and coke combustion residues using a hightemperature tube furnace combustion method with infrared absorption. American Society for Testing and Material. D 5016 (08). 2016.

16. Standard test method for sulfur in petroleum and petroleum products by energy dispersive X-ray fluorescence spectrometry. American Society for Testing and Material. D 4294. 2010.

17. Standard test method for determination of phosphorus, sulfur, calcium, and zinc in lubricationloils by energy dispersive X-ray fluorescence spectroscopy. American Society for Testing and Material. D 6481. 2014.

18. Standard test method for low sulfur in automotive fuels by energydispersive X-ray fluorescence spectrometry using a low-background 
proportional counter. American Society for Testing and Material. D 7212. 2013.

19. Standard test method for total sulfur in gaseous fuels by hydrogenolysis and rateometric colorimetry. American Society for Testing and Material. D 4468. 2015.

20. Standard test method for sulfur in petroleum products by hydrogenolysis and rateometric colorimetry. American Society for Testing and Material. D 4045. 2015 .

21. Standard test method for (thiol mercaptan) sulfur in gasoline, kerosine, aviation turbine, and distillate fuels (potentiometric method). American Society for Testing and Material. D 3227. 2013.

22. Standard test method for sulfur compounds in light petroleum liquids by gas chromatography and sulfur selective detection. American Society for Testing and Material. D 5623. 2014.

23. Standard test method for simultaneous measurement of sulfur compounds and minor hydrocarbons in natural gas and gaseous fuels by gas chromatography and atomic emission detection. American Society for Testing and Material. D 6968. 2015.

24. Perez-Cabero, M.; Rodriguez-Ramos, I.; Guerrero-Ruiz, A. J.; J. Catal. 2003, 215, 305.

25. Xie, J.; Sharma, P. K.; Varadan, V. V.; Varadan, V. K.; Pradhan, B. K.; Eser, S.; Mater. Chem. Phys. 2002, 76, 217.
26. Aso, H.; Matsuoka, K.; Sharma, A.; Tomita, A.; Energy Fuels 2004, 18, 1309.

27. Gonzalez, D.; Altin, O.; Eser, S.; Garcia, A. B.; Mater. Chem. Phys. 2007, 101, 137

28. Eser, S.; Venkataraman, R.; Altin, O.; Ind. Eng. Chem. Res. 2006, 45, 8946.

29. Rey, A.; Zazo, J. A.; Casas, J. A.; Bahamonde, A.; Rodriguez, J. J.; Appl. Catal., A 2011, 402, 146.

30. Doorn, J. V.; Bosch, J. L.; Bakkum, R. J.; Moulijn, J. A.; Stud. Surf. Sci. Catal. 1987, 34, 91.

31. Brown, S. D.; Ismail, K.; Snape, C. E.; Harding, A. W.; Jones, J. M.; Thomas, K. M.; Energy Fuels 1995, 9, 1104.

32. Tang, S.; Yang, C.; Peng, Y.; Yang, X.; Guo, J.; Xie, Y.; Tang, A.; Multipurp. Util. Miner. Resour. 2020, 2, 106.

33. Lacount, R. B.; Anderson, R. R.; Friedman, S.; Blaustein, B. D.; Fuel 1986, 66, 9093.

34. Renton, J. J.; Bird, D. S.; Int. J. Coal Geol. 1991, 17, 21.

35. Domazetis, G.; Raoarun, M.; James, B. D.; Liesegang, J.; Pigram, P. J.; Brack, N.; Glaisher, R.; Energy Fuels 2006, 20, 1556.

36. Ghauri, M.; Shahzad, K.; Khurram, M. S.; Jaffery, M. H.; Ali, N.; Khan, W. A.; Cliffe, K. R.; Energies 2017, 10, 782. 